\title{
PARA ALÉM DO SENTIDO DE LÍNGUA: A LEITURA COMO FRUIÇÃO E CONSTRUÇÃO DE CONHECIMENTO
}

\author{
Ilana da Silva Rebello \\ Doutora em Letras pela Universidade Federal Fluminense (UFF) \\ Professora Adjunta da Universidade Federal Fluminense (UFF) \\ ilanarebello@id.uff.br \\ Nadja Pattresi de Souza e Silva \\ Doutora em Estudos de Linguagem pela Universidade Federal Fluminense (UFF) \\ Professora Adjunta da Universidade Federal Fluminense (UFF) \\ nadja.pattresi@gmail.com \\ Rosane Santos Mauro Monnerat \\ Doutora em Letras (Letras Vernáculas) pela Universidade Federal do Rio de Janeiro (UFRJ) \\ Professora Titular da Universidade Federal Fluminense (UFF) \\ rosanemmonnerat@gmail.com \\ Isadora Eccard Bersot \\ Graduanda em Letras (Grego) pela Universidade Federal Fluminense (UFF) \\ isadorabersot@id.uff.br \\ Marcella Gomes Luna de Farias \\ Graduanda em Letras pela Universidade Federal Fluminense (UFF) \\ luanagalvao@uol.com.br \\ Monique Rohem Silva \\ Graduanda em Letras (Latim) pela Universidade Federal Fluminense (UFF) \\ moniquerohem@gmail.com
}

\section{RESUMO}

Este artigo tem como objetivo discorrer sobre a importância da leitura na escola, tendo como arcabouço-teórico pressupostos da Linguística Textual e da Teoria Semiolinguística de Análise do Discurso. Com base em algumas inquietações, verificar-se-á como dois importantes documentos oficiais - PCN e BNCC - pensam a prática da leitura na escola para, em seguida, refletir sobre a importância da leitura na escola e, consequentemente, sobre a necessidade de levarmos o aluno a ultrapassar o sentido de língua e chegar ao sentido de discurso (CHARAUDEAU, 1995). Por fim, será apresentado um relato de experiência, com o propósito de mostrar que a leitura significativa é possível e que tem como resultado a formação de leitores, já que a leitura deixa de ser um martírio para se tornar fonte de prazer e de conhecimento.

Palavras-chave: Linguística textual, Semiolinguística, leitura, escola.

\section{ABSTRACT}

This article aims at discussing the importance of reading at school based on the theoretical framework of Textual Linguistics and the Semiolinguistics Theory of Discourse Analysis. Starting from some concerns, it will be described how two important official documents - PCN and BNCC - present the reading teaching and learning process so that afterwards the importance of reading at school can be highlighted and consequently the need to take students to overcome the sense of language and reach the sense of discourse (CHARAUDEAU, 1995). Finally, an experience report will be presented with the purpose of showing that meaninful reading is possible and that it results in the formation of readers, since reading stops being a source of suffering and demotivation and becomes a source of pleasure and knowledge.

Keywords: Textual Linguistics, Semiolinguistics, reading, school. 


\section{Considerações iniciais}

Apesar da enorme importância da leitura e da interpretação na vida das pessoas, muitas vezes, a escola prioriza estratégias que levam à formação de decodificadores em vez de leitores, e a diferença está no modo de sentir e de perceber o texto. O leitor consegue ir além da leitura superficial e, por conseguinte, percebe o texto na sua relação com o contexto.

Diante disso, como formar leitores? Se a “educação é transformação do homem e do mundo" (SILVA, 2005, p. 77), como fazer com que o aluno perceba as sutilezas em um texto? Como levá-lo a ultrapassar a simples decodificação do texto?

A fim de refletir sobre algumas possibilidades de responder a esses questionamentos, neste artigo, inicialmente, traça-se um panorama acerca do processo de leitura de acordo com dois dos principais documentos oficiais que norteiam a Educação Básica no Brasil. Em seguida, apresenta-se uma discussão teórica sobre o ato de ler como um processo interacional de construção de sentidos, tendo em vista a formação de leitores, e não apenas de decodificadores da palavra, em associação com a relação proposta por Charaudeau (1995) sobre o sentido de língua e o sentido de discurso.

Na sequência dessa discussão à luz de princípios da Linguística Textual e da Semiolinguística, inclui-se o relato de experiência de uma prática que concebe a leitura como um processo significativo voltado à construção do conhecimento e à fruição.

\section{A leitura na escola e os documentos oficiais: os Parâmetros Curriculares Nacionais e a Base Nacional Comum Curricular}


Publicados a partir de 1997 e inicialmente voltados para o Ensino Fundamental', os Parâmetros Curriculares Nacionais (PCN) representaram um importante marco para a reflexão sobre o ensino e para a remodelação de práticas escolares com vista a formar cidadãos reflexivos e ativos, preparados para os desafios do mundo contemporâneo.

Organizados em torno das diferentes áreas curriculares, os PCN tiveram como mola propulsora a:

[...] necessidade de se construir uma referência curricular nacional para o ensino fundamental que possa ser discutida e traduzida em propostas regionais nos diferentes estados e municípios brasileiros, em projetos educativos nas escolas e nas salas de aula. E que possam garantir a todo aluno de qualquer região do país, do interior ou do litoral, de uma grande cidade ou da zona rural, que frequentam ${ }^{\mathrm{ii}}$ cursos nos períodos diurno ou noturno, que sejam portadores de necessidades especiais, o direito de ter acesso aos conhecimentos indispensáveis para a construção de sua cidadania (BRASIL, 1998, p. 9).

No que diz respeito à área de Língua Portuguesa, o documento destaca a centralidade do texto no processo de ensino-aprendizagem, pois uma das funções precípuas do ensino de língua é contribuir para que os alunos se tornem críticos e participativos no meio em que vivem. De acordo com os PCN:

Uma vez que as práticas de linguagem são uma totalidade e que o sujeito expande sua capacidade de uso da linguagem e de reflexão sobre ela em situações significativas de interlocução, as propostas didáticas de ensino de Língua Portuguesa devem organizar-se tomando o texto (oral ou escrito) como unidade básica de trabalho, considerando a diversidade de textos que circulam socialmente. Propõe-se que as atividades planejadas sejam organizadas de maneira a tornar possível a análise crítica dos discursos para que o aluno possa identificar pontos de vista, valores e eventuais preconceitos neles veiculados (BRASIL, 1998, p. 59). 
As diretrizes para o ensino de Língua Portuguesa são organizadas em três eixos, que correspondem a práticas de linguagem específicas e inter-relacionadas, a saber: prática de escuta de textos orais e leitura de textos escritos; prática de produção de textos orais e escritos e prática de análise linguística.

No que concerne à prática de escuta e leitura de textos escritos, defende-se uma concepção de leitura como processo de construção e negociação de sentidos, uma vez que a questão central dessa prática não reside na pura e simples decodificação de sons e palavras da língua por meio de textos, mas no trabalho amplo com a leitura que, entre outros conhecimentos e estratégias, se apoia também na decodificação. Em outras palavras, nessa perspectiva, a decodificação e a familiaridade com o sistema ortográfico, por exemplo, são vistos apenas como meios, e não fins em si mesmos.

Assim, tal atividade deve ser pautada pelo uso de gêneros diversos, com base em objetivos e no desenvolvimento de estratégias variadas de leitura. Os PCN sublinham a importância do trabalho com materiais autênticos em vez do uso de apostilas ou cartilhas produzidas artificialmente para se ensinar a ler, furtando ao aluno a (talvez única) oportunidade de entrar em contato com o universo da literatura, da palavra mobilizada com fins sociais e discursivos em textos concretos e reais na escola. De acordo com o documento, isso significa:

[...] trabalhar com a diversidade de textos e de combinações entre eles. Significa trabalhar com a diversidade de objetivos e modalidades que caracterizam a leitura, ou seja, os diferentes "para quês" - resolver um problema prático, informar-se, divertir-se, estudar, escrever ou revisar o próprio texto - e com as diferentes formas de leitura em função de diferentes objetivos e gêneros: ler buscando as informações relevantes, ou o significado implícito nas entrelinhas, ou dados para a solução de um problema (BRASIL, 1997, p. 41). 
Essa prática de leitura poderá, portanto, concorrer para a formação de leitores capazes de ler o que está escrito e também o que está implícito ou o que é sugerido pelos textos, realizando inferências, relacionando o que leem com conhecimentos prévios, validando e justificando a leitura com base nos textos e em diferentes estratégias, como se o material lido também funcionasse como um conjunto de pistas linguístico-discursivas para a interação e a produção de sentidos.

Em dezembro de 2017, veio a lume mais um documento basilar para a educação nacional. Em consonância com os PCN e também com os demais documentos que organizam o sistema educacional brasileiro, a Base Nacional Comum Curricular (BNCC) estabelece os conteúdos básicos e mínimos que devem fazer parte do currículo de escolas públicas e privadas em todo o Brasil.

Inicialmente voltado para a Educação Infantil e o Ensino Fundamentaliii, o documento também prevê o respeito às características e às especificidades culturais das diferentes regiões do país e indica que os conteúdos sejam organizados, de forma progressiva e gradual, em competências, habilidades e diferentes campos de atuação, que norteiam a escolha de gêneros diversos de acordo com as práticas de linguagem.

Quanto às práticas de linguagem, na área de Língua Portuguesa, os eixos em que se organizam são semelhantes aos que já foram mencionados em relação aos PCN: oralidade, leitura/escuta, produção (escrita e multissemiótica) e análise linguística/semiótica. Esta última "envolve conhecimentos linguísticos - sobre o sistema de escrita, o sistema da língua e a norma-padrão -, textuais, discursivos e sobre os modos de organização e os elementos de outras semioses" (BRASIL, 2017, p. 69).

O documento enfatiza a importância da fruição e também da variedade de gêneros no processo de ensino-aprendizagem, filiando-se a uma concepção de leitura 
sintonizada com a perspectiva sociointeracionista. Assim, à semelhança dos PCN, a BNCC também advoga pela centralidade do texto nesse processo. Como se lê no documento:

Assume-se [...] a perspectiva enunciativo-discursiva de linguagem, já assumida em outros documentos, como os Parâmetros Curriculares Nacionais (PCN), para os quais a linguagem é 'uma forma de ação interindividual orientada para uma finalidade específica; um processo de interlocução que se realiza nas práticas sociais existentes numa sociedade, nos distintos momentos de sua história' (BRASIL, 1998, p. 20). Tal proposta assume a centralidade do texto como unidade de trabalho e as perspectivas enunciativo-discursivas na abordagem, de forma a sempre relacionar os textos a seus contextos de produção e o desenvolvimento de habilidades ao uso significativo da linguagem em atividades de leitura, escuta e produção de textos em várias mídias e semioses (BRASIL, 2017, p. 65).

Defende-se, assim, que a leitura deve transcender a relação com o texto escrito e abrir-se para as múltiplas semioses que constituem, por exemplo, imagens estáticas e em movimento. Destaca-se, ainda, que a habilidade de leitura deve ser desenvolvida de forma contextualizada, gradual e progressiva dos anos iniciais do Ensino Fundamental até os anos finais do processo de escolarização.

Isso se concretiza pela articulação de diferentes fatores, entre os quais o "[...] uso de habilidades de leitura que exigem processos mentais necessários e progressivamente mais demandantes [...]" e a "consideração da diversidade cultural, de maneira a abranger produções e formas de expressão diversas, a literatura infantil e juvenil, o cânone, o culto, o popular, a cultura de massa, a cultura das mídias, as culturas juvenis etc. [...]" (BRASIL, 2017, p. 73).

Considerando o que determinam os dois documentos oficiais mencionados quanto ao ensino e à aprendizagem da leitura, discorre-se, na sequência, sobre a relevância da leitura no ambiente escolar. 


\section{A importância da leitura na escola}

Segundo Martins (1994, p. 34), "ensinar a ler não implica apenas alfabetizar ou propiciar o acesso aos livros", mas "conduzir" o leitor aos implícitos do texto. Nesse sentido, é por meio da leitura que o homem se torna sujeito, no momento em que é capaz de se fazer menos indecifrável, de romper com as grades do isolamento, de se evadir com o outro, sem, contudo, perder a sua individualidade.

Metaforicamente, a leitura pode ser entendida como uma ponte para a interação com o mundo. A falta da leitura pode imobilizar o homem no sentido de que ele terá mais dificuldade de entender o mundo e de tomar a sua palavra. Sendo assim, “[...] ler é [...] não só uma ponte para a tomada de consciência, mas também um modo de existir no qual o indivíduo compreende e interpreta a expressão registrada pela escrita e passa a compreender-se no mundo" (SILVA, 2005, p. 45).

A leitura possibilita que o leitor se posicione diante do texto, perceba as intenções do produtor, faça cálculos de sentidos possíveis e ultrapasse a simples decodificação. Quando o leitor é capaz de identificar os sentidos possíveis que estão escondidos sob significantes e consegue vislumbrar a intencionalidade do autor, relacionando o texto com o mundo, podemos dizer que chegou ao nível de uma leitura plena, o que chamaremos, mais adiante, de interpretação (sentido de discurso).

No entanto, segundo Colomer (2007, p. 64), "no nosso contexto escolar, [...], ensina-se a dar respostas objetivas e a ocultar a subjetividade, passando à margem do enlace do texto com o mundo do leitor." Ou seja, "a escola dedica grandes esforços para falar de livros e autores que, simplesmente, não fazem parte do mundo dos alunos. A barreira existente, então, é prévia e as possibilidades de êxito são bastante escassas" 
(COLOMER, 2007, p. 64). Tal estratégia dificulta tornar a aula de leitura um espaço de fruição, de troca e de questionamento.

Quando analisamos definições de leitura, percebemos que a ideia de produção e de construção está presente em todas. Porém, na prática, como produzir, como construir se o aluno é constantemente cerceado por estratégias castradoras do prazer que a leitura proporciona?

A título de exemplo, citamos duas definições de leitura:

O texto não preexiste a sua leitura, e leitura não é aceitação passiva, mas é construção ativa: é no processo de interação desencadeado pela leitura que o texto se constitui (SOARES, 1988, p. 1 apud DELL'ISOLA, 2001, p. 34).

A leitura é o momento crítico da constituição do texto, é o momento privilegiado da interação, aquele em que os interlocutores se identificam como interlocutores e, ao se constituírem como tais, desencadeiam o processo de significação do texto (ORLANDI, 1983, p. 173 apud DELL'ISOLA, 2001, p. 35).

Assim, percebemos, nas definições citadas por Dell'Isola (2001), palavras-chave como "construção ativa", "interação", "processo de significação", mostrando que ler é uma atividade muito mais complexa do que se imagina. Isso porque, na leitura de um texto, nem todas as informações se encontram explícitas.

O gráfico a seguir procura retratar a natureza da leitura, o que ocorre quando um sujeito estabelece o projeto de ler um texto e a resultante desse projeto. Identificar o propósito do produtor do texto permite que o leitor construa, com base em pistas fornecidas pelo texto, possíveis significados. Além disso, pelo gráfico, fica evidente que, 
quando o leitor consegue atribuir significados, ele é capaz de ver os horizontes do texto, ou seja, ampliar a sua leitura, entendendo as experiências trazidas pelo texto.

Gráfico 1 - Etapas do ato de ler

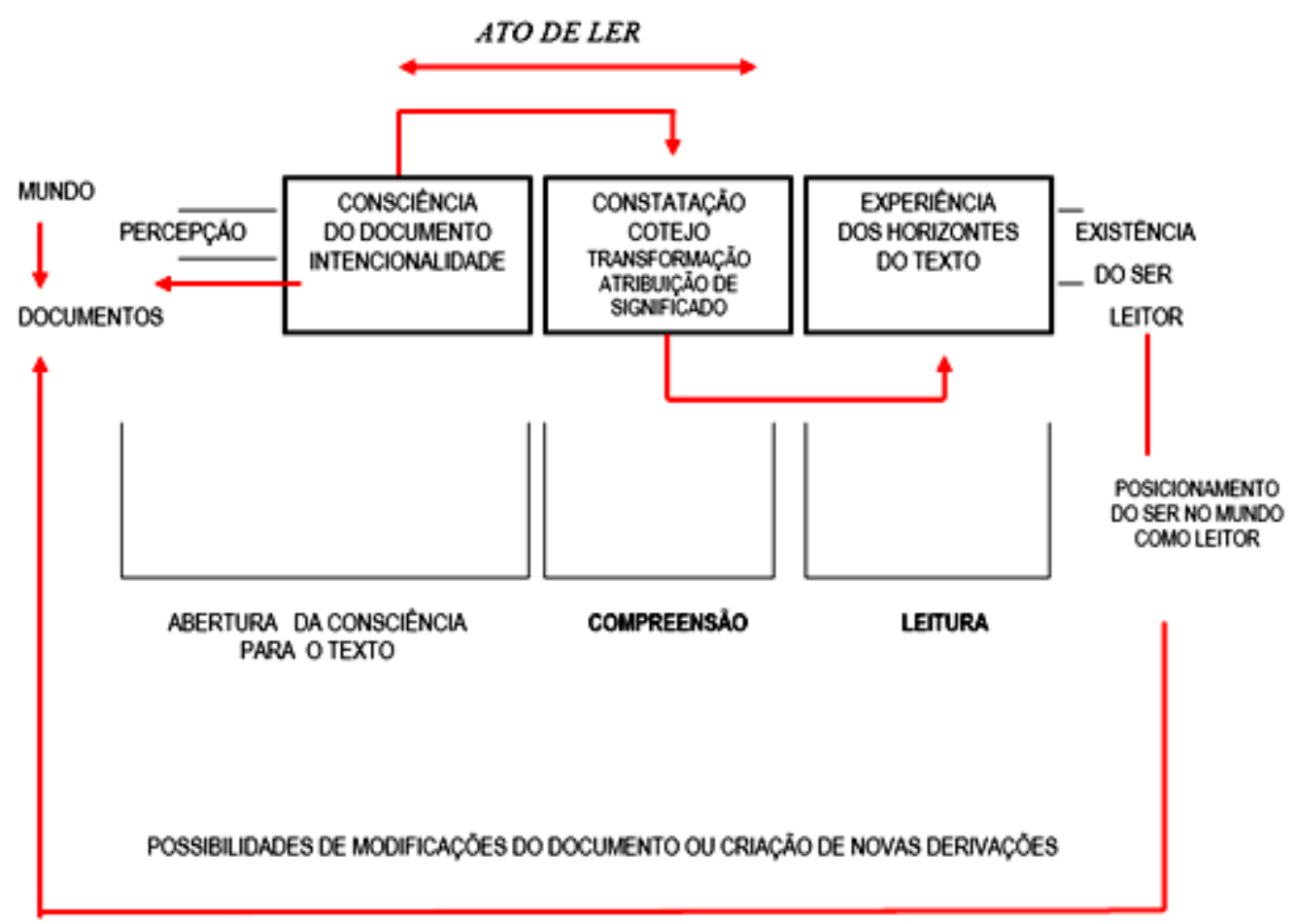

Fonte: Silva (2005, p. 92)

Explicando o paradigma acima, Silva (2005, p. 95) afirma:

$O$ ato de ler inicia-se quando um sujeito, através da sua percepção, toma consciência de documentos escritos existentes no mundo. Ao buscar a intencionalidade, o sujeito abre-se para possibilidades de significação, para as proposições de mundo que os signos do documento evocam ou sugerem.

Ao buscar a compreensão do texto, a partir das referências sugeridas pelos signos impressos que compõem o documento, o sujeito executa as atividades de constatação, cotejo e transformação. Na constatação, o sujeito situa-se nos horizontes da mensagem, destacando e enumerando as possibilidades de significação; no cotejo, o sujeito interpreta os significados atribuídos; na transformação, o sujeito responde aos 
horizontes evidenciados, re-elaborando-os em termos de novas possibilidades.

A leitura se manifesta, então, como a experiência resultante do trajeto seguido pela consciência do sujeito em seu projeto de desvelamento do texto. É essa mesma experiência (ou vivência dos horizontes desvelados através do texto) que vai permitir a emergência do ser leitor. Por sua vez, os novos significados apreendidos na experiência do leitor fazem com que este se posicione em relação ao documento lido, o que pode gerar possibilidades de modificação do texto evidenciado através do documento, ou seja, a incrementação dos seus significados.

Pelo exposto, o ato de ler, como afirma Silva (2005, p. 96), "sempre envolve apreensão, apropriação e transformação de significados, a partir de um documento escrito. Leitura sem compreensão e sem recriação do significado é pseudoleitura [...]". O autor ainda expõe algumas dúvidas sobre o trabalho que é desenvolvido com o texto nas escolas: “[...] Será que as escolas propõem leituras que levam à compreensão e recriação? [...] Será que as escolas possibilitam a reflexão e a tomada de posição, despertadas pelo ato de ler?" (SILVA, 2005, p. 96).

O que deveria ser fonte de prazer e de conhecimento acaba tornando-se um martírio, tendo em vista que a fruição é esquecida em prol da cobrança sistemática e, às vezes, aleatória de conteúdos literários que nem sempre fazem sentido para o aluno, que acaba relacionando a leitura a um questionário ou a uma prova.

A leitura, sendo compromisso de todas as áreas, deve permitir que o aluno aprenda não a repetir palavras, mas a dizer a sua palavra. Assim, para que isso ocorra, é necessário que o professor selecione bons materiais de leitura e leve o aluno a reconhecer e a utilizar estratégias ou pistas, que o auxiliem na busca do(s) sentido(s) de um texto.

\section{Aprender a ler para além do sentido de língua}


A leitura estabelece-se na interação autor-texto-leitor, processo por meio do qual os sujeitos se constroem e são construídos. Nesse sentido, o texto é o próprio lugar da interação e da constituição dos interlocutores, o que pressupõe implícitos que dizem respeito aos diferentes universos dos interlocutores, ou seja, aos seus contextos sociocognitivos.

Considerada dessa forma, a leitura constitui-se como evento comunicativo, operação altamente complexa, que envolve, além do processamento dos elementos linguísticos explícitos na materialidade do texto (código linguístico e forma de organização), a mobilização de um vasto conjunto de saberes, implicitamente envolvidos no processo, relacionados às experiências e conhecimentos dos interlocutores. Para Koch e Elias (2011), esses saberes constituem a "bagagem cognitiva" que o leitor já traz consigo ao entrar em interação com o texto.

A leitura, pois, como ato interenunciativo, pressupõe a presença de um leitor ativo que interage com o texto em busca da construção do seu sentido. Dizer que o leitor constrói o sentido do texto não significa dizer que o texto não tem sentido em si mesmo, mas que o significado que o leitor lhe atribui, determinado por suas experiências, pode ou não coincidir com o sentido que o autor lhe pretendeu dar.

Assim, a questão da compreensão e interpretação textuais assume grande relevância nos estudos sobre o texto. A Teoria Semiolinguística de Análise do Discurso, criada pelo linguista francês Patrick Charaudeau, oferece uma valiosa contribuição nesse aspecto, ao trazer à luz o binômio sentido de língua e sentido de discurso, que se articula, respectivamente, à diferença entre compreensão e interpretação.

No senso comum, os termos compreensão e interpretação podem ser considerados sinônimos. Na Teoria Semiolinguística, entretanto, verifica-se uma 
importante distinção entre eles, restringindo-se a compreensão ao sentido específico do termo. Segundo Charaudeau (1995, p.14),

[...] o termo compreensão pode ser tomado em um sentido amplo ou restrito. No sentido amplo refere-se ao conjunto do processo cognitivo realizado pelo sujeito face a um texto; no sentido restrito, refere-se a apenas uma parte desse processo que consiste em conhecer o sentido de língua que se encontra em um texto [...].

Assim, no processo da compreensão, o sujeito interpretante deve não só reconhecer os sentidos das palavras dentro de um referencial linguístico, bem como identificar as instruções de sentido mais prováveis, ou cálculo de probabilidades. A coesão textual deverá permitir ao sujeito executar as operações de identificação (nomear e conceituar os seres do mundo), qualificação (atribuir características aos seres), ação (agir ou sofrer as ações) e causação (revelar a causa de certos acontecimentos, por meio de modalizadores) (CHARAUDEAU, 2005, p. 14), que determinaram a construção do sentido de língua por parte do sujeito comunicante. Portanto, o processo de compreensão relaciona-se ao sentido de língua.

Já no processo de interpretação, o sujeito interpretante faz inferências, levando em consideração elementos situacionais, seguindo um processo semântico-cognitivo que consiste, "dentro de um movimento centrífugo de estruturação de sentido, em relacionar as palavras e sequências portadoras de sentido de língua às outras palavras e sequências registradas na memória do sujeito" (CHARAUDEAU, 2005, p. 13).

Vale lembrar que ninguém entende a totalidade significativa de um texto, já que há uma vasta gama de "potencialidades significantes que são parcialmente ativadas" pelos leitores e ativadas de maneiras diferentes, segundo o tipo de leitor. Por isso, deve- 
se buscar alcançar, ainda, a intercompreensão, que é uma suposição sobre o grau de reconhecimento entre o sentido de discurso projetado pelo sujeito comunicante e o construído pelo interpretante (CHARAUDEAU, 2008, p. 45).

Além de propor a importante distinção entre os termos compreensão e interpretação, a noção de intercompreensão, também introduzida pela Semiolinguística, leva ao entendimento da não transparência da linguagem e da construção de sentidos múltiplos, construídos com base nos saberes e crenças dos sujeitos de determinado projeto de comunicação.

Ao se analisarem esses conceitos, percebe-se, com nitidez, a distinção que há entre sentido de língua e sentido de discurso. A expressão sentido de língua relaciona-se, portanto, com a capacidade de os sujeitos envolvidos em determinada interação relacionarem um significante a um significado. Trata-se de reconhecer o sentido das palavras que resulta de uma categorização semântico-linguística.

O sentido de língua, então, refere-se ao mundo de maneira transparente, construindo uma imagem de um locutor-ouvinte ideal, ou seja, uma visão simbolizada referencial do mundo. Dessa forma, o sentido das palavras resulta de um processo semântico-cognitivo de ordem categorial que consiste, dentro de um movimento centrípeto de estruturação do sentido, em atribuir às palavras traços distintivos, caracterizando-as, segundo a rede de relações na qual esses traços se acham inseridos em suas relações sintagmáticas e/ou paradigmáticas (CHARAUDEAU, 1995, p. 12).

Por outro lado, o sentido de discurso corresponde à intencionalidade do sujeito comunicante, permitindo-Ihe passar do sentido de suas palavras ao sentido de seu discurso. Trata-se de um movimento centrífugo de estruturação de sentido, de ordem 
inferencial, que produzirá sequências de natureza conotativa, por meio da interdiscursividade.

Em suma, o ato de compreensão limita-se ao reconhecimento do sentido de língua, ao passo que o ato de interpretação consiste em relacionar esse sentido de língua com as condições que presidem à finalização pragmática da comunicação, ou seja, com o sentido de discurso.

\section{A leitura dentro da escola: um relato de experiência}

A atividade que será relatada foi desenvolvida no âmbito do Projeto de Iniciação à Docência (PID), que tem por objetivo proporcionar aos licenciandos de Letras da Universidade Federal Fluminense (UFF) oportunidades de atividade docente orientada desde o início da graduação. É um programa de aprimoramento que busca, sobretudo, um espaço de reflexão sobre ensino-aprendizagem de Línguas e Literaturas na perspectiva do profissional de Letras. Tendo como espaço de atuação a Sala de Leitura do Colégio Universitário Geraldo Reis, o projeto busca, então, avançar nas relações universidade - comunidade ao mesmo tempo que se procura oferecer ao licenciando de Letras a oportunidade de um contato maior com a verdadeira realidade daquele que se pretende um educador e não só um especialista em linguagem e língua.

A atividade relatada a seguir teve por objetivo estimular a criatividade e a socialização entre os alunos do 5 o ano do Ensino Fundamental. Conforme o planejamento da professora regente, deu-se continuidade ao trabalho com o livro Alice no país das maravilhas, de Lewis Carroll. Antes de introduzir o livro, a professora regente exibiu o filme para os alunos. 
Planejou-se uma atividade que, inicialmente, levasse os alunos a rememorar alguns conceitos aprendidos no decorrer do trimestre anterior, como adaptações, fanfics e elementos da narrativa. Por saber de antemão que a turma já conhecia os filmes baseados no livro, tanto o desenho assistido quanto o live-action - afinal, as adaptações para o cinema estão, em geral, entre as mais divulgadas e apreciadas, - apresentou-se a eles um material que provavelmente seria menos conhecido: um jogo de vídeo game chamado Alice: Madness Returns, lançado em 2011.

A experiência foi interessante, pois os estudantes reconheceram cenários do filme na capa do jogo e relataram diferenças percebidas na personagem Alice, como sua expressão facial e corporal, além da presença macabra do Gato Sorridente. Após esse primeiro momento, o tema fanfics veio à tona, gerando um debate.

Além da adaptação do livro para o jogo, apresentaram-se mais outras duas relacionadas à Alice: uma edição em mangá da Turma da Mônica no País das Maravilhas, história em quadrinhos favorita dos alunos; e uma história do Morcego Vermelho, personagem da Disney que lembra o Tio Patinhas (semelhança destacada pelos alunos), no mesmo País.

No terceiro momento, expôs-se uma lista com curiosidades sobre o famoso Gato Sorridente. Uma delas se destacou: a descoberta de que o Gato tinha uma dona, a Duquesa. Ela não é representada no filme, mas é ilustrada e descrita no livro.

Todo o trabalho desenvolvido no trimestre com Alice visou à produção final de uma HQ por parte dos alunos. Isso os motivou a consultar o livro que deu origem aos filmes, fazendo com que a curiosidade fosse além das adaptações e chegasse ao texto original. 
Precedendo a atividade final, as personagens da história e os elementos da narrativa foram relembrados. Depois dessa retomada de conhecimentos prévios, como uma motivação para a produção escrita que viria em seguida, fez-se um paralelo com as aulas de teatro que os alunos também têm. Sendo assim, propôs-se a criação de um texto narrativo em que cada aluno deveria escolher uma personagem do filme e escrever sua história de origem, incluindo sua idade, o local onde nasceu, além de dizer como ela chegou ao País das Maravilhas e o que achou da visita de Alice.

Apesar de alguns alunos, inicialmente, não compreenderem bem a atividade e produzirem resultados diferentes da proposta, ao final, constatou-se que todos participaram e entregaram suas criações. A produção foi individual, mas foi notável perceber a interação entre os alunos, mostrando e lendo voluntariamente suas histórias para os amigos, perguntando suas opiniões e pedindo sugestões. No final da aula, os alunos levaram para casa um paper toy do Gato Sorridente.

Com a atividade desenvolvida, a aula de leitura, além de estimular a criatividade e permitir a socialização, também possibilitou a fruição e a construção de conhecimento. Mais do que decodificadores, os alunos foram estimulados a serem leitores e a descobrirem o prazer que existe na leitura.

A atividade estimulou o processo de leitura descrito por Silva (2005), na medida em que os alunos, com base no conhecimento de mundo, ultrapassaram a leitura linear e desvelaram o emaranhado de sentido(s) latentes no texto, produzindo novos conhecimentos.

Além disso, ao vivenciarem os horizontes desvelados pelo texto (SILVA, 2005), também ultrapassaram o sentido de língua (compreensão), efetivando a verdadeira leitura que leva ao sentido de discurso (interpretação) (CHARAUDEAU, 1995). Na 
produção textual, semiotizaram o mundo (CHARAUDEAU, 2005), transformando o mundo bruto (conhecimentos aprendidos sobre narrativa, sobre a história da Alice no País das Maravilhas etc.) em mundo significado (HQ produzida em sala), como no exemplo a seguir.

Figura 1 - Parte de HQ produzida por alunos

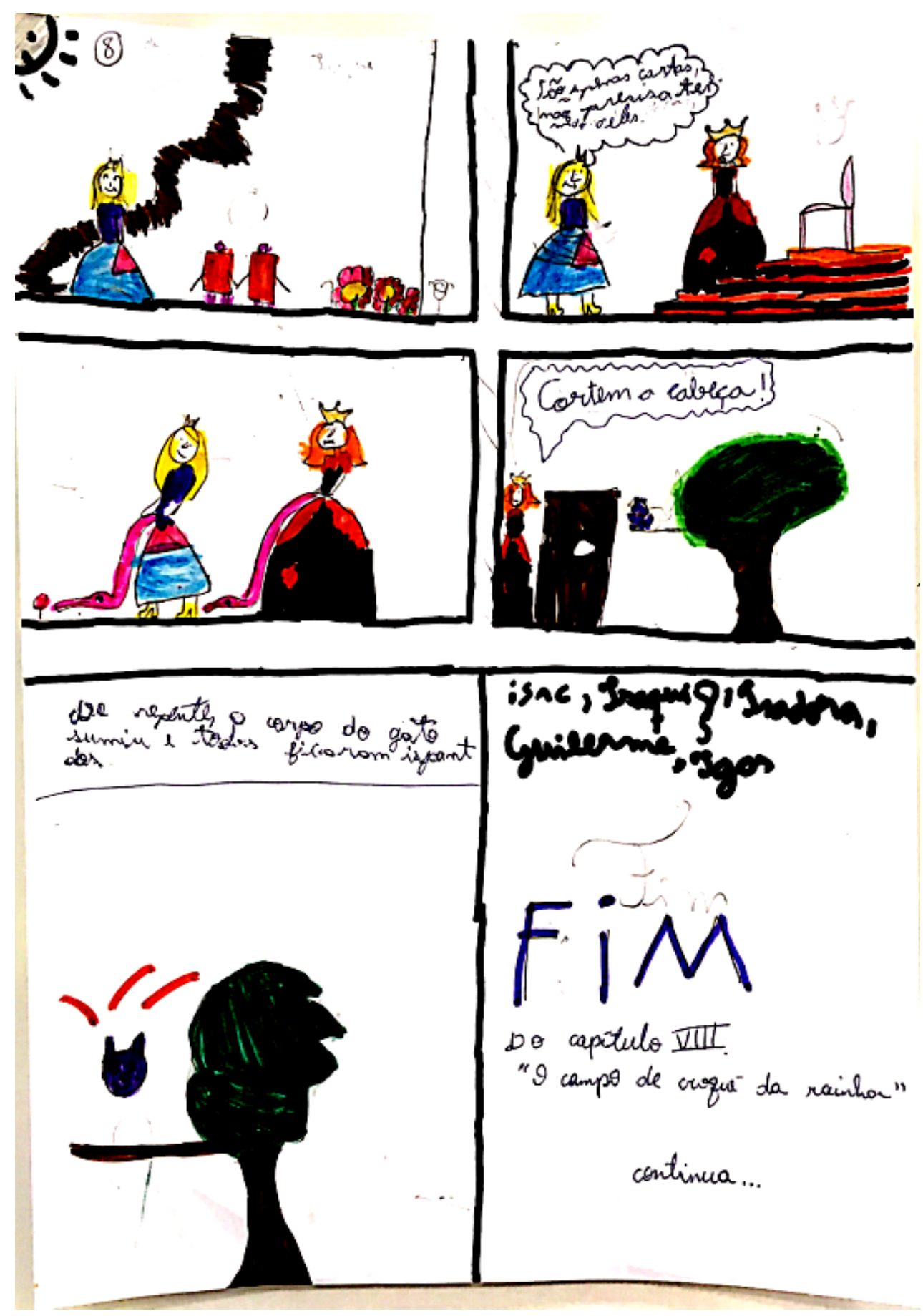


A cena retratada na figura 2 remete ao oitavo capítulo de Alice no País das Maravilhas, em que se relata a visita da protagonista ao campo de croquet da Rainha de Copas - uma ditadora cruel, conhecida por sua emblemática frase: "Cortem as cabeças!". Na ilustração, os alunos retrataram o primeiro encontro de Alice, ao chegar ao jardim, com os jardineiros da Rainha. Em seguida, na narrativa, Alice tenta tranquilizar a Rainha e convencê-la de que não é preciso temê-los, pois os jardineiros são apenas cartas de baralho. O temperamento explosivo da ditadora faz com que ela não tolere a ousadia da menina em dirigir-Ihe a palavra e, então, a Rainha ordena a decapitação da jovem.

No final, os alunos desenham o famoso Gato de Cheshire desaparecendo, tal como ele faz no término do capítulo. Essa façanha causa um verdadeiro rebuliço no jardim pois o felino também havia sido sentenciado à morte pela Rainha -, deixando em pânico os responsáveis pelo cumprimento da pena.

Portanto, como diz Antunes (2009, p. 206),

se desde o início, for dada aos alunos a oportunidade da leitura plena (do livro e do mundo) - aquela que desvenda, que revela, que lhes possibilita uma visão crítica do mundo e de si mesmos [...], uma nova ordem de cidadãos poderá surgir e, dela, uma nova configuração de sociedade.

É assim que pensamos que a atividade de leitura deve ser: simplesmente prazerosa e produtiva. Esperamos, desse modo, com este artigo, fomentar a discussão em torno da leitura na escola, tendo em vista que "o compromisso primeiro do professor de língua materna é auxiliar o aluno a tornar-se um leitor autônomo e um produtor competente de textos" (FIORIN, 1996, p. 9). 


\section{Considerações finais}

A fim de discutir a importância da leitura na escola, partiu-se de uma breve descrição sobre o ensino e a aprendizagem de tal processo com base em dois importantes documentos oficiais - PCN e BNCC. Em seguida, buscou-se discorrer sobre a relevância desse processo no contexto escolar, que pode e deve contribuir para que os estudantes superem o sentido de língua e atinjam o sentido de discurso.

Buscou-se relatar, neste trabalho, uma experiência realizada no âmbito do Projeto de Iniciação à Docência (PID) que envolve licenciandos de Letras da UFF e estudantes da Sala de Leitura do Colégio Universitário Geraldo Reis. Por meio de atividades que estimularam a leitura de variados textos e a interação com o material lido, bem como com os membros do grupo, produziu-se uma possibilidade de vivência significativa na escola.

Em consonância com o que defendem os documentos oficiais e as perspectivas teóricas aqui delineadas, com base no trabalho desenvolvido, a leitura parece ter deixado de ser apenas um objeto de ensino, muitas vezes fonte de angústia no ambiente escolar, para se tornar um objeto de aprendizagem, ou seja, uma prática instigante para os alunos, algo que verdadeiramente ganhasse sentido em sua experiência na escola e na vida de forma geral.

Ressalta-se, ainda, que o trabalho envolveu o contato com a literatura consagrada pela tradição e também o trabalho com gêneros multissemióticos, típicos da cultura contemporânea, como as $\mathrm{HQ}$ e o jogo de vídeo game. Além de levar a uma ampliação do repertório de leitura dos estudantes, as atividades partiram do que já conheciam para propor o contato com outras adaptações de uma narrativa clássica e para incentivá-los a 
descobrir o prazer da leitura como processo de fruição, de interação e de construção de conhecimento.

\section{Referências}

ANTUNES, Irandé. Língua, texto e ensino: outra escola é possível. São Paulo: Parábola Editorial, 2009.

BRASIL. Ministério da Educação. Parâmetros curriculares nacionais: língua portuguesa / Secretaria de Educação Fundamental. Brasília, DF: MEC/SEF, 1997.

. Ministério da Educação. Parâmetros curriculares nacionais: terceiro e quarto ciclos do ensino fundamental - introdução aos parâmetros curriculares nacionais / Secretaria de Educação Fundamental. Brasília, DF: MEC/SEF, 1998.

Ministério da Educação. Secretaria da Educação Básica. Base Nacional Comum Curricular. Brasília, DF: MEC, 2017.

CHARAUDEAU, Patrick. Les conditions de compréhension du sens de discours. Anais do I Encontro Franco-Brasileiro de Análise do Discurso, Rio de Janeiro: CIAD/UFRJ, 1995. Tradução livre.

. Linguagem e discurso: modos de organização. São Paulo: Contexto, 2008.

. Uma análise semiolinguística do texto e do discurso. In: PAULIUKONIS, Maria Aparecida Lino; GAVAZZI, Sigrid (orgs.). Da língua ao discurso. Rio de Janeiro: Lucerna, 2005. p. 11-27.

COLOMER, Teresa. Andar entre os livros. A leitura literária na escola. Tradução Laura Sandroni. São Paulo: Global, 2007.

DELL'ISOLA, Regina Lúcia Péret. Leitura: inferências e contexto sociocultural. Belo Horizonte: Formato Editorial, 2001.

FIORIN, José Luiz. Teorias do discurso e ensino da leitura e da redação. Gragoata, Niterói, v. 2, p. 7-27, jan./jul. 1997.

KOCH, Ingedore G. Villaça; ELIAS, Vanda Maria. Ler e compreender: os sentidos do texto. São Paulo: Contexto, 2011. 
MARTINS, Maria Helena. O que é leitura. São Paulo: Brasiliense, 1994.

SILVA, Ezequiel T. da. $O$ ato de ler: fundamentos psicológicos para uma nova pedagogia da leitura. 10. ed. São Paulo: Cortez, 2005.

Recebido em 27 de agosto de 2018.

Aceite em 29 de dezembro de 2018.

\footnotetext{
' Os Parâmetros Curriculares Nacionais - Ensino Médio foram publicados entre 1999 e 2002.

ii A grafia do documento foi atualizada de acordo com as normas ortográficas vigentes.

iii A BNCC - Ensino Médio foi entregue ao Conselho Nacional de Educação (CNE) em abril de 2018 e entrou em fase de audiências públicas pelo Brasil.
} 